\title{
ROMANIAN
}

NEUROSURGERY

\author{
Vol. XXXIV | No. 2 June 2020
}

\section{Assessment of malpractice litigation following spine surgery}

\author{
Gabriel lacob, \\ Alexandru Vlad Ciurea
}




\section{Assessment of malpractice litigation following spine surgery}

\section{Gabriel lacob ${ }^{1,2}$, Alexandru Vlad Ciurea ${ }^{1,3}$}

\author{
1 Professor of Neurosurgery, "Carol Davila" University of Medicine and \\ Pharmacy Bucharest, ROMANIA \\ ${ }^{2}$ Chief of Neurosurgery Clinic, Bucharest Emergency Hospital, \\ Bucharest, ROMANIA \\ ${ }^{3}$ Chief of Neurosurgery Clinic, Sanador Hospital Bucharest, RomANIA
}

\section{ABSTRACT}

Medical litigation in spine surgery is a serious concern today, with a high volume of clinical negligence claims, substantial financial cost and significant burden, who is threatening the future of this surgery.

Classical spinal surgery should be performed with very well documented indication, in order to improve the expected results, with clear aims: decompression of the neural elements of the spine from tightness, stabilizing the spine to protect the nerves, eliminate the pain resulting from abnormal loading from the different movements.

Spinal surgery today means a wide analysis, understanding and realization of spinal decompression, also osteosynthesis and fusions, using high-performance gestures, with increased addressability especially in the elderly, for a varied pathology, which involves anaesthetic-surgical risks, complications. In such a context, surgical damage does not necessarily result from an error or from surgical misconduct and the surgeon is not always responsible for the damage in the absence of a proven fault in the legal sense.

The paper aims to briefly review the main problems, but also useful recommendations to meet various challenges, expectations, maintaining the quality of life of each patient, reducing risks of getting sued, also to increase the odds of a successful defence.

In conclusion: education, vigilance, improved patient-safety strategies, investigation, implementation and sharing of lessons learned from litigation claims remain important components of spinal surgeons training, to reduce future cases of negligence and improve patient care, quality of life, as many of the cases of successful litigation had a preventable cause.

\section{Seneca: Errare humanum est, sed perseverare diabolicum} Murphy's law: If anything can go wrong, it will!

\section{INTRODUCTION}

Why spine surgery medico-legal aspects? Spinal surgery, made classic or minim invasive, means frequent, demanding high risks procedures, required for many people, especially for old people, performed for: trauma, degenerative, infectious, vascular, instability, functional procedures, especially for pain, as a condition: to improve the patients status, to avoid neurologic threatening of neurologic spine function.

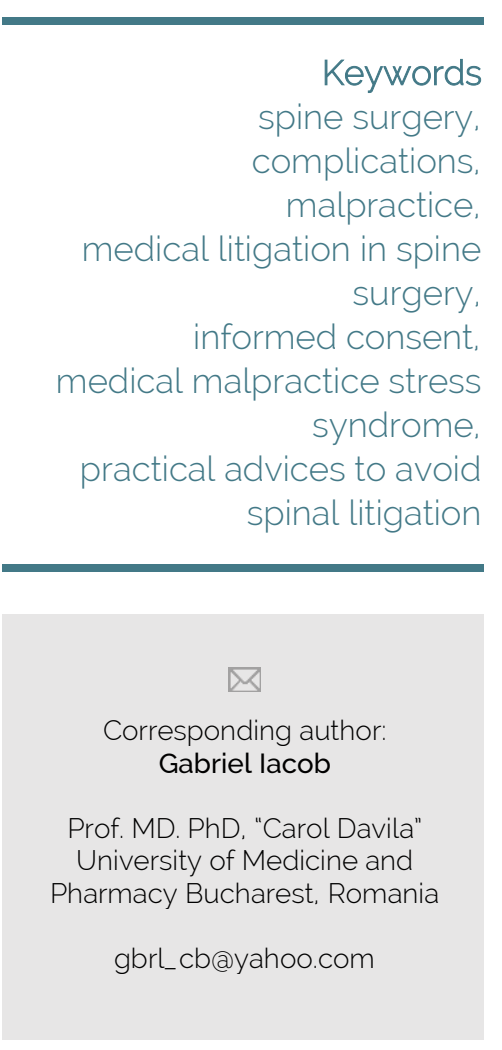

Copyright and usage. This is an Open Access article distributed under the terms of the Creative commons Attribution Non-Commercial No Commons Attribution Non-Commercial No
Derivatives License (https://creativecommons org/licenses/by-nc-nd/4.0/) which permits noncommercial re-use, distribution, and reproduction in any medium, provided the original work is unaltered and is properly cited.

The written permission of the Romanian Society of Neurosurgery must be obtained for commercial re-use or in order to create a derivative work.

ISSN online 2344-4959

(C) Romanian Society of Neurosurgery

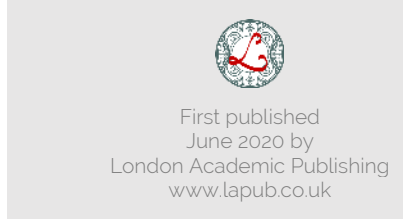


Spinal surgeons, whether of orthopaedic or neurosurgical backgrounds, encountered several adverse events, despite skills, patients compliance and expectations (1).

\section{DISCUSSION}

Medical litigation in spine surgery - a high-risk malpractice specialty is particularly influenced by the current litigation climate and it means (1):

- medical error - a consequence of a failure of a planned action to be completed as intended or the use of a wrong plan to achieve an aim: special technologies to fulfil decompression, stabilization with motion respect, using standard or minim invasive procedures, not always available in a hospital; a physician fails to act under the same circumstances to respect a standard of judgment, skill, diligence as any reasonable physician (2-4).This standard will be ascertained by appointed experts who will contrast the liable medical conduct to existing practice guidelines, statements of professional organizations and societies, use of leading books, scientific treaties and published articles;

- a breach of standard of care, negligence - a doctor's failure to meet this standard, does not necessarily result in liability. Bad outcomes may result even with the best of medical care; also technically unsuccessful surgery does not automatically mean a breach of standard of care. It's important to explain that bad results don't equate with malpractice and good results don't means that the patient has had the best of care! (4);

- causation covered a high range of causes pre, intra, postoperatively, to prove causal connection, the direct link between the negligence and damage;

- damage: proof of damage, directly resulted from the breach of the alleged standard of medical care

In 2005 alone, in the USA, 3,229 active certified neurosurgeons paid a total of $\$ 28$ million in malpractice claims, with the highest average payment per specialist surgeon $\$ 465,000$ (5).

1. Negligence claims in spinal surgery means more than 20,000 spinal operations/year in UK are the highest among other operations, more frequent and expensive: $+10 \%$ last 2 years (6). Spinal epidural abscess generates significantly higher plaintiff verdicts in cases with delay in diagnosis or treatment, in cases with paraplegic or quadriplegic patient (7).

2. In 2013 Hellsten et al. (8) mentioned adverse spinal events $17.4 \%$, to a cost of $\$ 21,000$ per case, $\$ 2.1 \mathrm{M}$ per year, 1,171 bed days every year, more than $50 \%$ due to 'minor' events.

3. In 2019 for plaintiff verdicts, the mean indemnity payment was median $\$ 753,057$; for settlements, the mean indemnity payment was median $\$ 547,935$. A neurological deficit was associated with a significantly greater likelihood of a favorable outcome for the plaintiff - $52.8 \%$ versus $32.1 \%$ for plaintiffs without neurological deficit (9). The average time to a decision for defendant verdicts was 5.1 years; for plaintiff rulings, 5.0 years; for settlements, 3.4 years. Poor consent, misdiagnosis, delays in the diagnosis and the treatment of a surgical complication predict legal case outcomes favoring the plaintiff (6), also catastrophic complications are linked to large sums awarded to the plaintiff and are predictive of rulings against the physician.

4. For physician defendants, the costs of settlements are significantly less than those of losing in court (1). Incidence of spinal malpractice claims is increasing: $56 \%$ compared to $39 \%$ head and/or brain, 5\% miscellaneous, with a multifactorial possible claim, many of them avoidable (10). Malpractice spinal claims are influenced by: the number and selection of patients, purpose of the procedure performed classic or minim invasive also by the social systems: compensation claims increasing the incidence rate, with a less patients intention to return to work as assurance payments are bigger (4).

In order for the doctor to be liable, the complaining patient must prove four things in the legal sense (6)(7):

- duty - did a physician-patient relationship exist?

- breach of duty - did the physician fail to meet the required standard of care - whether a body of responsible surgeons would have treated that patient the same way (Bolam test) the burden of the proof is on the plaintiff; 
- causation - did the physician's breach cause the patient's injury?

- damages - did the patient incur medical expenses, pain, suffering, loss of wages as a result of the breach?

There are several causes to litigations:

\section{A. Inappropriate decisions means:}

- poor communication despite patient's compliance, realistic expectation after surgery and the surgeon's skills lack of respect for patient and relatives, for the surgical team, the institution prestige linked to: misdiagnosis, bad indications, "unindicated surgery" it is often referring to the lack of concordance between clinical, radiological \pm neuro-physiological investigations, absence of marked psychosocial economic problems, failure of well conducted medical conservative treatment (1)(6);

- poor documentation: imaging's (mainly MRI) must be relatively recent (less than 3 months). In case of clinical changes or new clinical signs, MRI needs to be repeated before proceeding with the surgery (13);

- inappropriate preoperative patient assessment: comorbid conditions + the aging of the population - a growing concern for spine care in the $21^{\text {st }}$ century $(10)$. There are three major problems in elderly patients:

1. Failure due to wrong indication: poly-morbid patient, multi-operated patient (also other than spine surgery), diabetic patient with neuropathy, severe osteoporosis: 700,000 of these occur in the spine - more than in the hip and wrist combined !, obese patient, Parkinson, depressed patient, physically nonactive/active patient, patient in insurance battle waiting compensation. For elderly patients there are a very large pathology: metastatic and infectious diseases, degenerative spine: spinal stenosis, degenerative instability +/-adjacent segment problem (natural or iatrogenic), discogenic, cervical myelopathy, spondylolisthesis, arthritis, adult degenerative scoliosis, muscular insufficiency (fatty degeneration); difficult recovery (12);

2. Failure due to wrong biology mostly patient and /or surgeon's judgement related; sometimes spinal surgery for geriatic patients unnecessary, too much, or too little;

3. Failure due to wrong biomechanics mostly patient and also its biology and /or surgeon's judgement related (11).

- surgeons' expertise: a check list could be established and the steps are followed regularly before starting and during the surgery technique (sign in - prior to induction, time out - prior to skin incision, sign out - prior to drape removal), wrong judgement of own capabilities and skills, lack of expertise, wrong choices of technology (implants, instrumentation, surgical technique) + risks unexplained, failure to recognize the clinical signs and symptoms of complications, inappropriate delegation of procedures to junior doctors(13). Legal finding: the majority claims are from patients with no medical negligence, only 3\% of patients who suffered negligence filed a claim. (6)

\section{B. Failure to obtain consent (6):}

Consent should be done by the consultant; to be legally valid for examination or operation should met three conditions: must be given knowingly, freely and voluntarily, the patient or legal entities must be capable of giving legal consent, the patient should be sufficiently informed to make a considered decision. It's mandatory to discuss immediately after surgical indication is sustained: surgery risks against conservative options; especially to avoid complications, expectations for patients with old, severe neurologic deficits, to patients with low resources to recuperate; ex: lumbar disc or stenosis surgery is for leg pain not back pain, surgical fusion as last resort is not wise, $10 \%$ are worse after fusion.

\section{Wrong patient (14):}

- patient biology - age, hypertension and cardio vascular disease, diabetes, patient over 60 years with hemorrhagic risks especially after Aspirin, Plavix, smoking and pulmonary disease; also ASA grad $1-9.1 \%$, ASA grade $4-31.3 \%$. In cases of elderly patients with spinal cord tumours (15) age increase in significant morbidity for more than 64, 5 fold; in cases with elderly patients with cervical discs and myelopathy, an operation performed to a patient aged $>65$ yrs may increase mortality 14 fold, if the patient aged $>84$ yrs mortality increase 44 fold. 
- adequate conservative treatment? MRI if considering malignancy, sciatica/cauda equina syndr, infection, fracture, ankyl. spond., inflammatory disorders, referral for surgery (13), avoid operation delay (6)

- planning operation: think always to do it right the first time!

D. Wrong/stupid surgeon (14):

- wrong-level surgery, wrong side: always perform fluoroscopy before skin incision, before entering the canal; wrong positioning rate is estimated at $4.2 \%$, but is found to be $15.7 \%$ on control CT;

- wrong procedure: poor surgical performance: inadequate decompression, wrong technology despite right procedure and patient

- wise selection of radiation exposures in spinal surgery, safe operating procedure achieving a good balance between patient care and radiation safety, minimize the high fluoro technique, always use ALARA concept: As Low as Reasonably Achievable (16)(17)

\section{- think to the best patient position:}

- each position carries some degree of risk for haemodynamic and physiologic changes; also complications, risks magnified in anaesthetised patient due to loss of ability to compensate or communicate (18);

- prone position during spinal surgery should be made with the patient's head raised, in order to minimize facial and per orbital edema, avoiding eyeball compression especially after prolonged position, which may generate peri-operative blindness and litigation both for surgeon and anesthesiologist, ex: $0.03 \%$ after spinal fusion (19);

- all possible compression and traction points on the face, protecting neck position, trunk and limbs using protection pads to cover pressure points avoiding:

- ulnar nerve compression at the elbow - the most common;

- peroneal nerve injuryat the fibular neck is possible in any patient positioning, inducing paresthesia or severe motor impairment with drop foot;

- uni or bilateral femoral cutaneous nerve involvement results in meralgia paresthetica

- brachial plexus stretch injury.
- general anesthesia (18) with care especially during intubation to elderly patients with myelopathy or severe cervical stenosis, hyper flexion or extension, using the Philadelphia collar with fiber optics intubation, even under intra operative monitoring; maintaining a stable hemodynamic, avoiding ischemia by hypo perfusion with medullary insults, compensating rapidly any blood loss during hemorrhagic procedures

\section{E. Possible complications:}

- general causes which can evolve to death (20-22): deep venous thrombosis, pulmonary embolism, cardio-respiratory failures, abdominal vessel injury if sudden unexplained drop in blood pressure, abnormal bleed coming from the disc space, ileus, sepsis with chest/urinary infections, operating room fires (19) in USA 50-100 events/yr, 1-2/yr fatal, fire triad, location: $34 \%$ airway, $28 \%$ head or face, $38 \%$ on/or inside patient, heat/ignition source: cautery/laser/fiber optic light cord, fuel: drapes/ET tube/alcohol prep/hair $/ \mathrm{O}_{2}$ build up under impervious drape, especially for cervical spine, oxidizer: oxygen/nitrous oxide/air.

- acute or delayed neurologic deficits related to surgery (23)(24):

- direct iatrogenic medullary and radicular insults in procedures performed without spinal cord monitoring: MEPs, SSEPs, Nim Eclipse, or by hypo perfusion - arterial pressure $<80 \mathrm{~mm} \mathrm{Hg}$, especially in cases with myelopathy, medullary atrophy or ossification of the posterior longitudinal ligament estimated at 0.2 to $0.9 \%$.

- Cervical disk surgery with medullary decompression for myelopathy entails elevated risk, affecting the $\mathrm{C} 5$ root with deltoid impairment in 2.3 to $6.7 \%$ of cases (short sheat, subject to traction by medullary mobilization after decompression, inducing spinal cord retractionin surgical interventions restoring lordosis).

- Complex surgical procedures for spinal deformity of the thoracic and lumbar spine, to correct: sagittal deformity - see three-column resection osteotomies with pedicle subtraction osteotomies and vertebral column resections may generate paraplegia $0,55 \%-1,78 \%$.

- High grade lumbar spondylolisthesis may generate $11,8 \%$ with neurologic complications especially to the $L 5$ root; cauda equina syndrome 
following decompression for lumbar spinal stenosis, disc herniation: incidence of $2.8 \%$.

- latrogenic medullary and radicular insults could appear after poor positioning - estimated at $4.2 \%$, but is found to be $15.7 \%$ on control CT or per- or postoperative implant mobilization: screws, inter body cages, a.s.o.

- subsequent stoke: estimated at 3.8\% on the left and $1.8 \%$ on the right side after iatrogenic surgical trauma to the vertebral artery $0,3 \%$;

- recurrent laryngeal nerve injury with dysphonia, as the most common postoperative complaint in anterior cervical approaches;

- Horner syndrome due to injury to the cervical sympathetic trunk is a very rare complication of anterior cervical decompression and fusion, the incidence rate is between 0,2 to $4 \%$ mainly after revision surgery;

- retrograde ejaculation from damage to the hypo gastric plexus during anterior approach of the lumbar spineis estimated between 0,42 to $4,1 \%$.

\section{- Local complications:}

- implant related dysphagia in cervical disc herniation;

- lymphocele after anterior lumbar interbody fusion;

- dural tear (25-27) are very frequent during spine surgery (1-15\%), versus $7,7 \%$ in cases with neurological complications, three-fold higher in revision surgery, may generate CSF collections (pseudomeningocele), also intracranial hypotension, acute subdural hematoma, tonsillary herniation; leak must be treated seriously and rapidly! Primary repair suturing using microtechnique, if larger than $3 \mathrm{~mm}$, 6/0 suture, cover with: grafts (fat, muscle, fascia, blood patch), tissue sealents, fibrin glue, synthetic membrane; hermetic closure of the various planes, antibiotherapy are necessary, postoperative drainage after dural tear is controversial;

- radiculopathy: recurrent disc prolapse, ectopic bone/stenosis, fragments end plate prep, symptomatic epidural adhesions, TLIF retraction, multiple surgeries, inflammatory BMP reaction, BMP Ectopic Bone (28)(29) in spinal fusion 92.8\%, off label 85\%, 16.6\% ALIF, 30.0\% PLIF/TLIF, 20.4\% Postlat,13.6\% Cervical, 3.9\% T/L; no statistical correlation ectopic bone vs. increased leg pain, few cases of neurologic impairment of from ectopic bone;

- bleeding (17)(28)(30) it can occur damaging the arterial feeder in a rich vascularized vertebral tumor, through epidural varices, rarely by damage to an arterial vessel - see during discectomy. Postoperative bleeding could be: residual, discovered incidental or even symptomatic with different topography: epidural, paravertebral, even intradural. Main causes are: bad hemostasis, uncontrolled high blood pressure during operation, coagulopathy, drugs; ex. in cervical area is rare 0.2\%-1.9\%, may cause airways obstruction, requiring evacuation 0.1$0.4 \%$; in lumbar area is about $5,6 \%$. Best solutions are: meticulous dissecting and hemostasis, drain use, pay close attention to the patient's supervision even in ICU, quick evacuation;

- local seroma;

- instability (13)(17)(31-33) - avoid thinning the pars and aggressive facetectomy, junctional degeneration/instability (fusion disease);

- improper use of instrumentation (31-33): misplaced instrumentation - most frequent are lateral, may generate pedicle breaches $6.7 \%$ of screws; percutaneous fluoroscopically or navigation guided pedicle screw placement is safe and accurate, revision is rarely required; may increase the rate of CSF leakage, than without instrumentation 16\% versus $3,5 \%$, nonunion of the fusion or pseudoarthrosis, hardware malpositioning;

- infections (19)(28): especially in immunocompromise patients: diabetic, renal failure, HIV, etc, consider prophylactic antibiotherapy. More frequent infections appear as a complication of CSF leakage cases in nearly $1 / 4$ th of cases. There are several clinic entities: wound infection with postoperative abscess, spondylodiscitis, osteomyelitis, epidural collections, fungal meningitis: Exserohilum Rostratum, Aspergillis Fumigatus, Cladosporium from CSF after epidural steroid injection, 19 days post injection: fever, stiff neck;

- neuropathic pain, chronic pain corticalization, failed back surgery syndrome (13)(34)(35). Such entities can be generated by all previously mentioned complications. Patient selection is more important than most of the technical problems in FBSS (correct assessment is needed to get an accurate diagnosis, recurrent disc herniation or instability should be treated, no treatable cause, spinal cord stimulation may help improving patient's pain and functions;

- vertebroplasty may generate complications 3.7\% of cases, kyphoplasty $0.3 \%$ of cases (17)(36): severe pulmonary embolism of PMMA: 
hypertension, hypercapnia, loss of responsiveness, asymptomatic diffuse pulmonary embolism, neural and vascular complications after cement leakage inside the vertebral canal, silent leaks $30 \%-70 \%$ of patients, most are undetected by the surgeon.

F. What kind of operation: classic or minim invasive spine surgery. "MISS" is an acronym for the term: minimally invasive spine surgery, synonym: "LISS" less invasive spine surgery, endoscopic spine surgery $=$ efficient surgery with minimum of iatrogenic trauma, but not minimal surgery: minimal access \& techniques spine surgery, percutaneous, even using microscope as a part of a less invasive technology (37-39). The current focus on "MISS" refer to several "trendy" procedures, in the early phase of a "concept shift" (39), still met with skepticism, disbelief, hostility by many neurosurgeons for safety reasons, but more accurate.

Such procedures are using advances in access technology: optical systems (endoscopes, microscopes), navigation guided surgery, specialized retractor systems, hybrids, robotics, new generation of implants suitable for minimal access by anterior/posterior surgery, new solutions for fusion: cages, bone harvesting tools, bone substitutes, 3-d prosthesis; designed to solve a pathological process as using standard open procedures for less pain, morbidity, disability, facilitates faster recovery, improves back muscle function.

\section{WHAT DOES "MISS" MEAN TODAY?}

Advantages $(40,44)$ :

- small incisions- more aesthetics, appealing -some procedures can be performed as outpatient surgery;

- accurate fluoroscopic images with $X$ ray exposure or by navigation-guidance;

- theoretical better quality of life: shorter hospital stay, structure-sparing, or perhaps structurepreserving, a "MISS" by products are operative time, reduced tissular distruction, less pressure on muscles using minimally invasive spinal retractors compared to open retractors and reduced scar (periradicular \& skin), less blood loss, infection, disability; faster recovery, functional ability to return to normal activity, to work;

- long term pain control, minimal requirements for narcotic pain medications;
- may reduce or perhaps eliminate the development of adjacent segment disease;

- high expectations even to elderly, obese people with a complex spinal problem, such as deformity or trauma;

\section{Drawbacks and limitations (45)(46):}

- technically more demanding, longer operative time;

- less working space, extension and quality of direct spinal decompression, placing cross-links, long rods, less surface area of bone exposed for fusion cases

-limitations by pathology: possible spinal injuries associated with neurological deficits, see: spondyloptosis, severe multi-level stenosis, en-bloc removal of tumour masses, severe deformities;

- acute complications 10\%, 12\% reoperations: bleeding, 5.3\% dural tear with CSF fistula, 2.6\% fracture of an inferior facet - for lumbar spinal stenosis, TLIF may result in poor fusion without BMP, $10.5 \%$ transient neurological complications (47);

- radiation exposure with fluoroscopy (48) with poor radiological support - esp AP;

- education long steep learning curve, the intraoperative complication rate is highest between the $3 r d$ and the 6th year of training;

- availability;

- cost: expensive hardware, hospital stay it could be economic (49)(50);

- "Maximal Intra-operative Surgical Stress" (51).

\section{"MISS" recent evidence:}

- More frequent MISS indications (12): degenerative disc disease - herniated disc, lumbar spinal stenosis, spinal deformities such as scoliosis, spinal infections, spinal instability including spondylolisthesis, vertebral compression fractures, reconstruction with internal fixation, resection of spinal or paraspinal tumours.

- Performed with microscope or endoscope there are several MISS procedures (12)(52)(53), ex:

- cervical procedures: posterior foraminotomy, transarticular C1C2 screw fixation;

- thoracic procedures: foraminal discectomies, percutaneous pedicle screw fixation;

- lumbar procedures: discectomies, posterolateral interbody fusion PLIF, midline lumbar interbdy fusion MIDLF, transforaminal lumbar interbody fusion TLIF, extreme lateral lumbar 
interbody fusion DLIF (XLIF), anterior lumbar interbody fusion ALIF.

- For discectomy: micro discectomy (MD) vs tubular(52): no difference (the mean duration of surgery was 34 min shorter for conventional MD; the incidence of dural tear was $6.5 \%$ in MD group and $10.4 \%$ in early TD and decreased to $7.4 \%$ in late TD group, possible more leg pain, low-back pain, at 2 years with tubular) (53).

- For lumbar spinal stenosis: bilateral micro decompressive laminotomy, as minimally invasive endoscopic bilateral decompression with a unilateral approach (endo-BiDUA) for elderly patients (54)(55).

- For posterior lumbar fusion: significant advantages over traditional open procedures in the obese population, smaller incisions, less tissue trauma and quicker recovery, higher radiation exposure 84 s vs 37 s, may reduce or perhaps eliminate the development of adjacent segment disease (56-58). Revision TLIF identical results: less blood loss, less postoperative back pain at the second day postoperatively, same surgical time, higher radiation exposure 79 s vs 39 s (58).

- Adult spinal deformity correction with circumferential minimally invasive surgery and hybrid techniques result in overall reoperation rates of $27.9 \%$ and $33.8 \%$, respectively, at minimum 2 -year follow-up. Junctional failures are more common after hybrid approaches, while pseudarthrosis/fixation failures happen more often with circumferential minimally invasive surgery techniques. Early reoperations were less common than later returns to the operating room in both groups, but circumferential minimally invasive surgery demonstrated less risk of infection and early reoperation when compared with the hybrid group (60).

Practicing a good spinal surgery is not a guarantee to being hit with a medical malpractice lawsuit; nobody is immune from medical malpractice. Most spinal surgeons are not well prepared to deal with bad consequences of medical malpractice, they are perceived as a "wound to the heart", that may lead to frustrated, dissatisfied patients; also to several consequences: loss of reputation and significant supporters, lack of knowledge about the potential process and outcomes, loss of livelihood, control, assets.
Such situations may lead to "Medical Malpractice Stress Syndrome", expressed by psychological symptoms: anxiety, irritability, tiredness, restlessness, difficulty in concentration, excessive worry, may occupy more than $50 \%$ of working hours, tense muscles, insomnia, depression and by physical illness, at work and at home; dissatisfaction, to burnout of the medical practice, early retirement or even may generate extreme reaction, deep depression leading to suicide (1)(4)(59)(61).

Fear of lawsuits encourages defensive medicine, a defensive attitude, affecting patients (61):to restrict practice, not only to demanding procedures, also for emergency or trauma, to move their practice to a state with "better" malpractice conditions, in detriment of patients losing chances to receive the accurate treatment in the needed time; negatively influence any investment from the medical community, to consider retirement, rather than continue to practice in the face of increasing insurance costs, especially in that states with high malpractice claims and insurance premiums - so called "crisis" states.

\section{CONCLUSIONS AND PRACTICAL ADVICES}

Medical malpractice litigation in spinal surgery is one of the most stressful events of the life of any physician, but also a survivable and surmountable event to made you a stronger and better doctor, indeed, as Churchill said "there is only one answer to defeat, the victory". As a general remark, many claims in spinal surgery are avoidable (62-65); however, to reduce medical malpractice stress, vulnerability to potential litigation, negligence, some advices should be retained:

- good documentation and patient selection is required;

- the technique must be adapted both to the patient, to resources and facilities in your hospital;

- limit your activity, avoiding doing something outside of your expertise;

\section{To reduce risk of getting sued it is necessary:}

- never regret to lose effort and time to improve communication skills, communicating openly, explaining the patient to complete carefully the informed consent exposing clearly expectations, desired outcome, also possible complications. In more than $70 \%$ of litigations to improve situation, if a complication occurs, it's mandatory to justify in the record, explaining how, why it appeared; 
- discuss non-surgical option, if necessary, thinking twice and choose without delay a procedure with a lower complication rat;

- achieve a safe and efficient operation .

\section{To increase the odds of a successful defence:}

- keep a good communication with the patients, their relatives; don't avoid the patients or hide the facts- all hidden information it will be found; most patients simply want to know what happened and most important knows you care (4), always remember: "the Court is after the Proof and not The Truth"; demonstrate that what occurred was a complication rather than a deviation from the medical standard;

- visit the patient more often! - convey empathy, welcome the patient, maintain eye contact, let them tell their story, work to help the patient recover, making him a very strong defendant No attorney wants to put time and money necessary to pursue litigation into a case involving unavoidable complications, rather than negligence;

- try to keep the patient away from the attorney's office to pursue the claim against you;

- in difficult cases, always think to an ancient Romanian saying: "it's better to accept a mutual agreement, instead of a fair judgment";

- avoid doing something new that you are not adequately trained for, operating in careless way, also possible conflicts of interest with the insurer;

- temperate young surgeon's enthusiasm - not a head of their surgical skill;

- be actively involved in the defense team, discuss your ideas and suggestions with your lawyer but follow their instructions;

- knowledge is power: support education, training or new techniques at any level \& any age, professional support, local medical societies and associations, look for supportive 2-nd opinion from international professional medico-legal committees, seek advice from experienced colleagues, consultants, qualified malpractice lawyers experts, attend supportive educational meetings, enrol in risk management seminars, read available materials on litigation stress support, seek support education, training or new techniques at any level \& any age, professional support, local medical societies and associations, look for supportive 2-nd opinion from international professional medico-legal committees.
- demonstrate that what occurred was a complication rather than a deviation from the medical standard.

\section{CONFLICTS OF INTEREST}

The authors of this paper state that they have no conflict of interests to disclosure.

\section{ABbreVIations}

$\mathrm{CT}$ : computer tomography

MRI magnetic resonance imaging

ASA; American Society of Anaesthesiologists' classification of physical health

ALARA concept: As Low as Reasonably Achievable

TEP: pulmonary troboembolism

ET tube: endotracheal tube

MEPs: motor evoked potentials

SSEPs: somatosensory evoked potential

NimEclipse: a spinal and cranial neuro monitoring system (Medtronic)

BMP: human bone morphogenetic protein

ALIF: Anterior lumbar interbody fusion

PLIF/TLIF: posterior lumbar interbody fusion/thoracolumbar interbody fusion

FBSS: failed back surgery syndrome

PMMA: Poly methyl methacrylate

MISS: minimally invasive spine surgery

LISS: less invasive spine surgery

MD: micro discectomy

TB: tubular discectomy

endo-BiDUA: endoscopic bilateral decompression with a unilateral approach

\section{REFERENCES}

1. Daniels A.H., Ruttiman R. et al. - Malpractice litigation following spine surgery, Journal of Neurosurgery Spine 2017, 27(4):1-6.

2. Eloy JA, Svider PF, et al. - Comparison of plaintiff and defendant expert witness qualification in malpractice litigation in neurological surgery. J Neurosurg 2014, 120:185 -190.

3. Daniels A.H., Ruttima R. et al. -Malpractice litigation following spine surgery, Journal of Neurosurgery Spine 2017, 27(4):1-6.

4. lacob G, Majer C. - Reflections on medical malpractice stress disorders in Neurosurgery, Romanian Neurosurgery 2012, XIX 4: 247-250.

5. Betsy van Die - Study Analyzes How the Malpractice Environment Impacts Practicing Neurosurgeons, AANS Communications Department, 2008 28, (312) 949-3205.

6. Ameen A.A. - Negligence Claims in Spinal Surgery, 5 years Experience - 14th Dubai Spine Conference 2013.

7. DePasse J.M., Ruttiman R et al. - Assessment of malpractice claims due to spinal epidural abscess, J. Neurosurg. Spine 2017, 27(4), 476-480. 
8. Hellesten E.K., Handbidge M.E. - An economic evaluation of perioperative adverse events associated with spinal surgery, Spine J. 2013, 13(1):44-53.

9. Ahmed S.A., DeFroda S. F. , et al. - Malpractice Litigation Following Traumatic Fracture, J.Bone Joint Surg. Am 2019, 3;101(7):e27.

10. Rovit R.L., Simon A.S. et al. - Neurosurgical experience with malpractice litigation: an analysis of closed claims against neurosurgeons in New York State, 1999 through 2003, Neurosurgery 2007 106(6):1108-1114.

11. Hamdan T.A. - Perils and Pitfalls in Cervical Spine Surgery, 14th Dubai Spine Conference 2013.

12. Aebi M. - Complex Spine Surgery in the Elderly and its Pitfalls and Complcations, 14th Dubai Spine Conference 2013.

13. Msaddi A.K., Majer C - Minimizing side effects in microdiscectomy, 14th Dubai Spine Conference.

14. Bolger C. - When Things go Wrong in Spinal Surgery, the spectre of the problem, 14th Dubai Spine Conference 2013.

15. Patil C., Patil T., et al. - Complications and outcomes after spinal cord tumor resection in the United States from 1993 to 2002, Spinal Cord 2008, 46, 375-379.

16. SamaraeeA.Al - Radiation Safety in Spine Surgery, 14th Dubai Spine Conference 2013.

17. Zerbi A. - Radiation exposure in spine surgery (surgeons and patients), 14th Dubai Spine Conference 2013.

18. Raoof N. - Anesthesia and positioning complications, 14th Dubai Spine Conference 2013.

19. Wong D. - Patient Safety in Spine Surgery, 14th Dubai Spine Conference 2013.

20. DeVivo M.J., Black K.J. - Causes of death during the first 12 years after spinal cord injury, Arch.Phys. Med. Rehabil. 1993, 74 (3); 248-254.

21. Soden R.J., Walsh J. et al. - Causes of death after spinal cord injury, Spinal Cord 2000, 38(10): 604-610.

22. Connely N, Silverman D.G. - Review of Clinical Anesthesia, Lippincott Williams \& Wilkins 2013, ch.4., 17-18.

23. Nanda A. - Complications in Neurosurgery, Elsevier 2019, 30, E-Book.

24. Roccamo G., Haydon J.H. - Medicine in the litigation process, Carswell, 1999, 395.

25. Andrews et al. -. Cerebellar Herniation and Infarction as a Complication of an Occult Postoperative Lumbar Dural Defect, AJNR 1995.

26. Sciubba,et al. - Acute Intracranial Subdural Hematoma Following a Lumbar CSF Leak Caused by Spine Surgery, Spine (Phila Pa 1976). 2005 Dec 15;30(24):E730-2.

27. Wong et al. - Dural tears secondary to operations on the lumbar spine: Management and results, J Bone Joint Surgery1998, 1728-1732.

28. Stadler J.A., Wong A.P. et al. - Complications associated with posterior approaches in minimally invasive spine decompression, Neurosurg. Clin N.Am 2014, 25(2):233245.

29. Haid R, Branch C Posterior lumbar interbody fusion using recombinant human bone morphogenetic protein type 2 with cylindrical interbody cages. Spine J 2004;4:527-539.

30. Sokolowski M.J., Garvey T.A, et al. - Prospective study of postoperative lumbar epidural hematoma, Incidence and Risk factors, Spine 2008, 33,108-113.

31. Abumi K. et al. - Complication of pedicle screws fixation in reconstructive surgery of cervical spine, Spine 2000, 25(8), 962-969.

32. Fessler R. et al. - Breach Rate of Percutaneous Lumbar Pedicle Screws Using Fluoroscopic Guidance, 14th Dubai Spine Conference 2013.

33. Alfawareh M. - Safety and Complication Avoidance in Cervical Spine Tumors Surgery, 14th Dubai Spine Conference 2013.

34. lacob G. - The failed back surgery syndrome - Archives of the Balkan Medical Union, march 2009, vol. 44, 1, 51-55

35. lacob G. - The failed back surgery syndrome, Conferinta Nationala a Asociatiei Romane pentru studiul durerii, Bucuresti, 26-27 octombrie 2017.

36. Sagi H.C., Yuan A.Y. - Vertebroplasty and Kyphoplasty in the treatment of osteoporotic vertebral compression fractures, in Haher T.R, Merola A.A.- Surgical techniques for the spine, Thieme, 2003, ch.16, 79-85.

37. Szpalski M. - Does Size Matter ? What is the evidence for MISS, 14th Dubai Spine Conference 2013.

38. Jaikumar, S. et al. - Minimally Invasive Surgery of the Spine: History of Minimally Invasive Spine Surgery, Neurosurgery 2002, 51, 5, S2,1-S2-14.

39. Fessler R. G. - Mininally invasive spine surgery, Neurosurgery, 2002, 51,2, S2-iv.

40. Rosen DS, Ferguson SD, et al. - Obesity and self-reported outcome after minimally invasive lumbapinal fusion surgery. Neurosurgery 2008, 63, 956-960.

41. Knight RQ et al. - Direct lateral lumbar interbody fusion for degenerative conditions: early complication profile. J Spinal Disord Tech 2009, 22,34-37.

42. Gorek et al. - Minimally invasive surgery of the spine: less is more. Semin Spine Surg 2013:23:2-8.

43. Bolger C - Minimally invasive spinal surgery, Is it worth the effort ? 14th Dubai Spine Conference2013.

44. Smith Z.A., Fessler R.G. - Paradigm changes in spine surgery-evolution of minimally invasive techniques, Nature Reviews Neurology 2012, 8, 443-450.

45. Park $Y$ et Al. - The effect of a radiographic solid fusion on clinical outcomes after minimally invasive transforaminal lumbar interbody fusion. Spine J. 2011,11(3),:205-212.

46. Raco A. - Miss procedures, Advantages and limitations, 13th Dubai Spine Conference 2013.

47. Ikuta K., Tono O. - Surgical complications of microendoscopic procedures for lumbar spinal stenosis, Minim Invasive Neurosurg. 2007, 50(3), 145-149.

48. Bindal RK et al.- Surgeon and patient radiation exposure in minimally invasive transforaminal lumbar interbody fusion. J Neurosurg Spine, 2008 ,9(6),570-573.

49. Ritz JP. - MIS and the econimics of it. Can MIS be cost efficent from a bussiness point of view?, Chirurg. 2007, 78(6), 501-504, 506-510.

50. Van den Akker ME et al. - Tubular diskectomy vs 
conventional micro diskectomy for the treatment of lumbar disk-related sciatica: cost utility analysis along side a double-blind randomized controlled trial, Neurosurgery 2011;69:829-35.

51. Hamid N. A. - Safety and Limitations of MIS in Lumbar Spine Surgery 14th Dubai Spine Conference 2013.

52. Bhatia P.S., Chhabra H.S. et al. - Microdiscectomy or tubular discectomy: Is any of them a better option for management of lumbar disc prolapse, J Craniovertebr Junction Spine 2016, Jul-Sep; 7(3): 146-152.

53. Arts M.P., Brand R. et al. - Tubular diskectomy vs conventional microdiskectomy for the treatment of lumbar disk herniation: 2-year results of a double-blind randomized controlled trial, Neurosurgery 2011 Jul;69(1):135-144.

54. Celik S.E. et al. - Microdecompressive laminotomy with a 5-year follow-up period for severe lumbar spinal stenosis J Spinal Disord Tech, 2010.

55. Komatsu J., Muta T. et al. - Tubular surgery with the assistance of endoscopic surgery via a paramedian or midline approach for lumbar spinal canal stenosis at the L4/5 level, Journal of Orthopaedic Surgery 2018, 26(2), 18.

56. Rosen D.S., Ferguson S.D. et al. - Obesity and selfreported outcome after minimally invasive lumbapinal fusion surgery, Neurosurgery 2008, 63, 956-960.

57. Knight R.Q. et al - Direct lateral lumbar interbody fusion for degenerative conditions: early complication profile, J
Spinal Disord Tech 2009, 22, 34-37.

58. Wang J Zhou Y. et al. - Comparison of one-level minimally invasive and open transforaminal lumbar interbody fusion in degenerative and isthmic spondylolisthesis grades 1 and 2, Eur Spine J 2010, 19, 1780-1784.

59. Makhni M.C., Park P.J.et al. - The medico-legal landscape of spine surgery: how do surgeons fare?, Spine J.2018, Feb;18(2), 209-215.

60. Eastlack RK, Srinivas R, et al. - Early and Late Reoperation Rates With Various MIS Techniques for Adult Spinal Deformity Correction, Global Spine J., 2019;9(1):41-47.

61. Lekovic G.P., Harrington T.R. - Litigation of missed cervical spine injuries in patients presenting with blunt traumatic injury, Neurosurgery 2007, 60:516-523.

62. Fager C.A. - Malpractice issues in neurological surgery, Surgical Neurology 2006, 65(4): 416-421.

63. Steele L., Mukherjee S. et al. - Extent of medicolegal burden in neurosurgery - An analysis of the National Health Service Litigation Authority Database, $\mathrm{Br}$ J Neurosurg, 2015;29(5):622-629.

64. Hamdan A, Strachan RD et al. - Counting the cost of negligence in neurosurgery: Lessons to be learned from 10 years of claims in the NHS, Br J Neurosurg, 2015; 29(2):169-177.

65. Banna SE, Catano A. - Complications of Spine Surgery and Litigations - Managing Malpractice Risk. J ClinExpOrthop. 2015, 1:3. doi: 10.4172/2471-8416.100003. 